\title{
Color Origins in Langatate Crystals
}

\author{
Maroua Allani ${ }^{1,2^{*}}$, Narjès Batis ${ }^{2}$, Abdeldjelil Nehari $^{3}$, Hugues Cabane ${ }^{4}$, \\ Kheirreddine Lebbou ${ }^{3}$, Christophe Pecheyran ${ }^{5}$, Corine Reibel ${ }^{6}$, Jean-Jacques Boy ${ }^{1 *}$ \\ ${ }^{1}$ FEMTO-ST Institute, UFC, CNRS, ENSMM, UTBM, 25000 Besançon, France \\ 2 INSAT, Université de Carthage, BP 676, 1080 Tunis cedex, Tunisia \\ ${ }^{3}$ ILM Institute, UCBL, 69000 Lyon, France \\ ${ }^{4}$ Cristal Innov, 73800 Sainte-Hélène du Lac, France \\ ${ }^{5}$ LCABIE - IPREM -Université de Pau - 64053 Pau Cedex 9, France \\ ${ }^{6}$ Institut Charles Gerhard, Université de Montpellier, 34000 Montpellier, France
}

\begin{abstract}
Langatate $\mathrm{La}_{3} \mathrm{Ga}_{5.5} \mathrm{Ta}_{0.5} \mathrm{O}_{14}$ is piezoelectric crystal from langasite family, commonly grown by Czochralski method from Ir crucible. Langatate crystals of different colors (colorless, orange, green) have been studied by optical spectroscopy in UV-Visible $(200-800 \mathrm{~nm})$ and IR $\left(7000-1000 \mathrm{~cm}^{-1}\right)$ ranges. Furthermore, the effects of irradiation by ultraviolet laser source $(\lambda=266 \mathrm{~nm})$ and post-growth annealing in $\mathrm{N}_{2}+\mathrm{O}_{2}$ atmosphere have been investigated. The yellow-orange is mainly due to an absorption centered in the ultraviolet that extends into the blue of the visible spectrum (250-500 nm). The IR optical absorption spectra of Langatate crystals exhibit an absorption band at $5370 \mathrm{~cm}^{-1}$. It seems linked to a point defect responsible for color. The intensity of the absorption band at $3430 \mathrm{~cm}^{-1}$ increases after annealing in oxygen containing atmosphere. We have discussed phenomenon that can occur simultaneously in langatate crystals and produce very similar colors which are related to structural defects. First, metal ions impurities (as Iron, Titanium...), whose presence is previously confirmed by femtosecond laser ablation coupled with ICP-MS spectroscopy, can contribute to langatate color. Second, ultraviolet absorption leads us to think about charge transfer phenomenon such as $\mathrm{O}^{2-} \rightarrow \mathrm{Fe}^{3+}$ and/or $\mathrm{Fe}^{3+}-\mathrm{Fe}^{3+}$ pair transitions. Third, the irradiation by ultraviolet $(\lambda=266 \mathrm{~nm})$ laser source locally color the langatate sample by the creation of color centers. Origins of color centers, particularly those related to oxygen vacancies, $\left(V_{O^{\prime}}, 2 e^{\prime}\right)^{x}$, are discussed. And, finally, point defects changes the band gap of langatate, leading to extend the absorption to visible light regions.
\end{abstract}

Keywords: annealing, color, color centers, charge transfer, impurities, langasite family crystals, optical spectrometry, point defects, ultraviolet irradiation.

\footnotetext{
* Corresponding author email: maroua.allani@ens2m.fr jiboy@ens2m.fr

DOI : https://doi.org/10.21467/ias.2.1.12-19
} 


\section{Introduction}

Owing to its very interesting piezoelectric properties and thermal stability, langatate $\mathrm{La}_{3} \mathrm{Ga}_{5.5} \mathrm{Ta}_{0.5} \mathrm{O}_{14}$ crystal (LGT) seems to be the best candidate to substitute quartz crystal for frequency output devices [1]. In fact, these applications require homogeneous crystals with reproducible physical properties. For that, before manufacturing acoustic devices (sensors, transducers, actuators or ultra-stable resonators), we control the quality of the crystal, using accurate techniques to reveal structural defects [2] [3]. Indeed, point defects, such as impurities and oxygen vacancies significantly affect the physicochemical properties (optical, electrical, piezoelectric...) and induce the crystal color.

Langatate crystals (LGT), commonly grown by the Czochralski method from a ternary melt of $\mathrm{La}_{2} \mathrm{O}_{3}-$ $\mathrm{Ga}_{2} \mathrm{O}_{3}$ and $\mathrm{Ta}_{2} \mathrm{O}_{5}$ using an iridium crucible, differ from colorless to yellow-orange or pale-green [4] [5] depending on growth and post-growth treatment conditions. LGT crystals without subsequent annealing differs from colorless to yellow-orange crystals, depending on growth atmosphere. LGT grown under $\mathrm{Ar}$ [6] [7] or $\mathrm{N}_{2}$ [8] are colorless, while those grown under $\mathrm{Ar}+\mathrm{O}_{2}$ are orange [6] [9] [10] [11] and yellow [12] [7]. After vacuum annealing, the LGT samples become colorless and orange colored after air annealing [13] [4] [5]. The authors [7] [14] have suggested that the oxygen present in the growth and annealing atmospheres is responsible for the crystal color linked by the authors [11] [5] [4] to the presence of oxygen vacancies in the structure. According to Buzanov et al. [6], LGT crystals color depends not only on oxygen vacancies but also on cation vacancies and charge exchange in cations. In the opinion of the authors [15], LGT crystals contain iridium ions, which induce its color on the basis that LGT crystals grown from a Pt crucible in air were colorless [6]. However, Taishi et al. [14] obtained orange crystals by Bridgman growth in Pt crucible.

In this study, basing on chemical and spectroscopic analyses, we discuss point defects arising during growth and post-growth treatments and inducing LGT color. For our study, we have selected differently colored langatate (LGT) samples from various suppliers.

\section{Materials and Methods}

\subsection{LGT Samples}

We have selected langatate (LGT) crystals from different suppliers. Langasite $\mathrm{La}_{3} \mathrm{Ga}_{5} \mathrm{SiO}_{14}$ (LGS) has been added for comparison. Details of growth, annealing conditions and color are tabulated in table 1. From the ingots, we cut wafers appropriate to each characterization technique. Moreover, some measurements have been achieved on ingot 'CI6' before annealing ' $\mathrm{ba}$ ' and after annealing ' $a \mathrm{a}$ '. The Figure 1 presents photos of samples cut from the ingots.

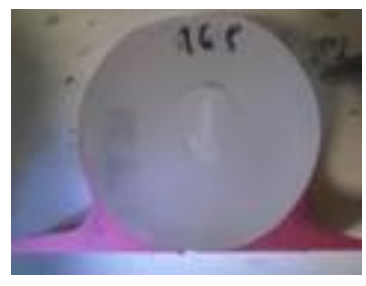

1)

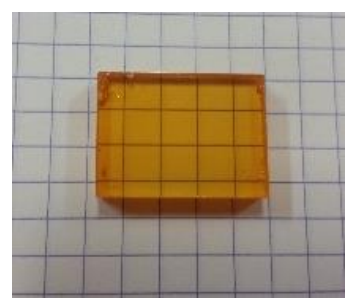

3)

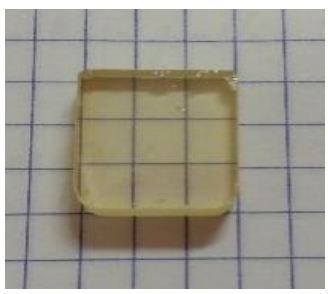

5)

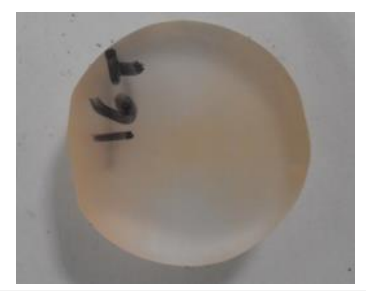

2)

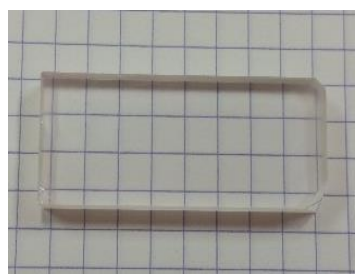

4)

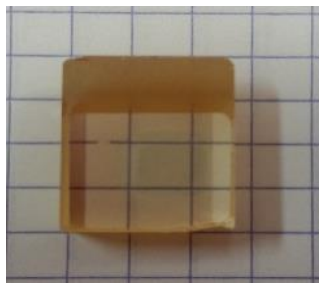

6)

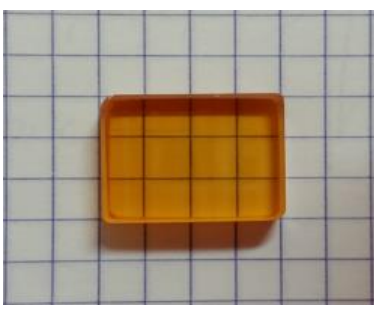

7)
Figure 1: Photos of langatate (LGT) and langasite (LGS) samples cut from ingots: 1) CI6 ba, 2) $C I 6 a a, 3) F n, 4) C K$, 5) $F o, 6) M 19$, 7) LGS. 
Allani et al., Int. Ann. Sci.; Vol. 2 Issue 1, pp: 12-19, April 2017

Table 1: Growth and post-growth treatment conditions of LGT samples and LGS from different suppliers.

\begin{tabular}{|c|c|c|c|c|}
\hline $\begin{array}{c}\text { Sample } \\
\text { reference }\end{array}$ & $\begin{array}{c}\text { Growth } \\
\text { axis }\end{array}$ & $\begin{array}{c}\text { Growth } \\
\text { atmosphere }\end{array}$ & Annealing & Color \\
\hline CI6 ba & $\mathrm{X}$ & $\mathrm{N}_{2}$ & Before annealing & colorless \\
\hline $\mathrm{CI} 6$ aa & $\mathrm{X}$ & $\mathrm{N}_{2}$ & $\mathrm{~N}_{2}+<0.1 \% \mathrm{O}_{2}, 1400^{\circ} \mathrm{C}, 24 \mathrm{~h}$ & $\begin{array}{c}\text { heterogeneous } \\
\text { light orange }\end{array}$ \\
\hline Fn & $\mathrm{Z}$ & $\mathrm{Ar}+1 \% \mathrm{O}_{2}$ & Air, $1250{ }^{\circ} \mathrm{C}$, several days & bright orange \\
\hline $\mathrm{CK}$ & $\mathrm{Z}$ & $\mathrm{N}_{2}$ & unannealed & colorless \\
\hline Fo & $\mathrm{Z}$ & unknown & unknown & light orange \\
\hline $\mathrm{M} 19$ & $\mathrm{Z}$ & $\mathrm{N}_{2}+0.5 \% \mathrm{O}_{2}$ & unannealed & bright orange \\
\hline LGS & $\mathrm{Z}$ & $\mathrm{Ar}+1 \% \mathrm{O}_{2}$ & Air, $1250^{\circ} \mathrm{C}$, several days & \\
\hline
\end{tabular}

\subsection{UV-Visible and IR Spectroscopy}

Point defects significantly affects the optical properties and they can be revealed by optical spectroscopy. The optical spectra of LGT and LGS samples with plane and parallel polished surfaces (thickness 4 to $5 \mathrm{~mm}$ ) were recorded in the wavelength range from 200 to $800 \mathrm{~nm}$ on a Lambda 900 UV-Visible spectrometer and in the range 7000 to $1500 \mathrm{~cm}^{-1}$, on a PerkinElmer Frontier FT-IR spectrometer. Moreover, UV-Visible and IR spectra of LGT and LGS samples were recorded after irradiation with $266 \mathrm{~nm}$ picosecond laser from Teem Photonics and after annealing in oxygen containing atmosphere for LGT 'CI6' sample.

\section{Results}

\subsection{UV-Visible Spectroscopy}

The characteristic transmission spectra in UV-Visible ranged from 200 to $800 \mathrm{~nm}$ of LGT crystals from the different suppliers are shown in Figure 2.

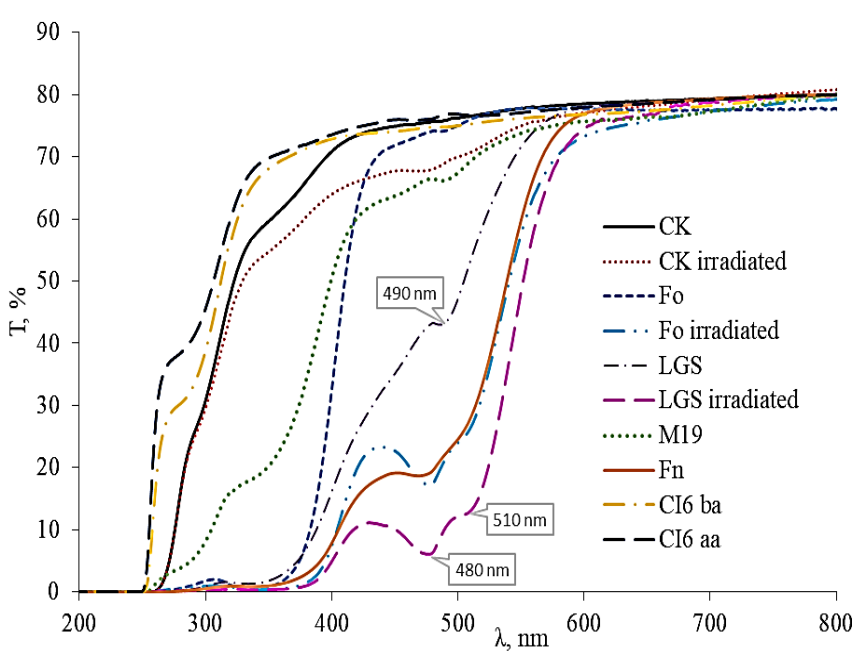

Figure 2: $U V$-Vis transmission spectra of LGT and LGS samples.
The yellow-orange of LGT crystal is caused mainly by an absorption centered in the ultraviolet that extends into the blue of the visible spectrum (250-500 nm).

The LGT CI6 aa spectrum exhibits a pronounced intrinsic absorption edge around $256 \mathrm{~nm}$. For LGT $\mathrm{CK}$, a shift of the intrinsic absorption edge to a higher wavelength of $270 \mathrm{~nm}$ is observed. The absorption band at $280 \mathrm{~nm}$ in the spectra of CK and CI6 was recorded by authors of [5] [16] and attributed to "La vacancies" $\mathrm{V}_{\mathrm{La}}$ "'. The weak and wide absorption band at around 330-340 $\mathrm{nm}$ observed in the transmission spectra of CK was attributed [5] [16] to oxygen vacancies $\mathrm{V}_{\mathrm{O}} \cdot$.

An absorption band at $\lambda \sim 490 \mathrm{~nm}$ is observed in LGS and LGT Fo and M19 spectra was previously attributed to $\mathrm{F}$ centers $\left(\mathrm{V}_{\mathrm{O}} \cdot{ }^{*}\right.$, 2é) and to orange coloration [16]. The defect responsible for the absorption band at $450 \mathrm{~nm}$ can be at the origin of the green color of LGT Fo. A spread and a shift to higher wavelength $\lambda \sim 350-380 \mathrm{~nm}$ of the intrinsic absorption edge are observed in the transmission spectra of LGS sample, LGT Fn and Fo. Comparing LGS and LGT Fo spectra, before and after ultraviolet irradiation, we note that the absorption band at $\sim 490 \mathrm{~nm}$ splits into two more intense absorption bands at $\sim 480$ and $\sim 510$ $\mathrm{nm}$, which appear also, with lower intensity, in the spectrum of irradiated LGT CK. For LGT CI6, we note that annealing in oxygen containing atmosphere decreases the intensity of the absorption band at 280 nm.

\subsection{IR Spectroscopy}

The characteristic transmission spectra in IR range from 7000 to $1500 \mathrm{~cm}^{-1}$ of LGT crystals from different suppliers are shown in Figure 3. IR absorption spectra of colored LGT ( Fo, Fn, M19) and LGS samples exhibit an absorption peak at $5370 \mathrm{~cm}^{-1}$, whose intensity increases with the color. 
This sharp absorption peak seems linked to a defect responsible to the crystal coloration. The variation of the absorption band intensity is related to the variation of the defect density as shown in Figure 3. The intensity of the absorption band at $3430 \mathrm{~cm}^{-1}$ increases after annealing in oxygen containing atmosphere [17] , Figure 3.

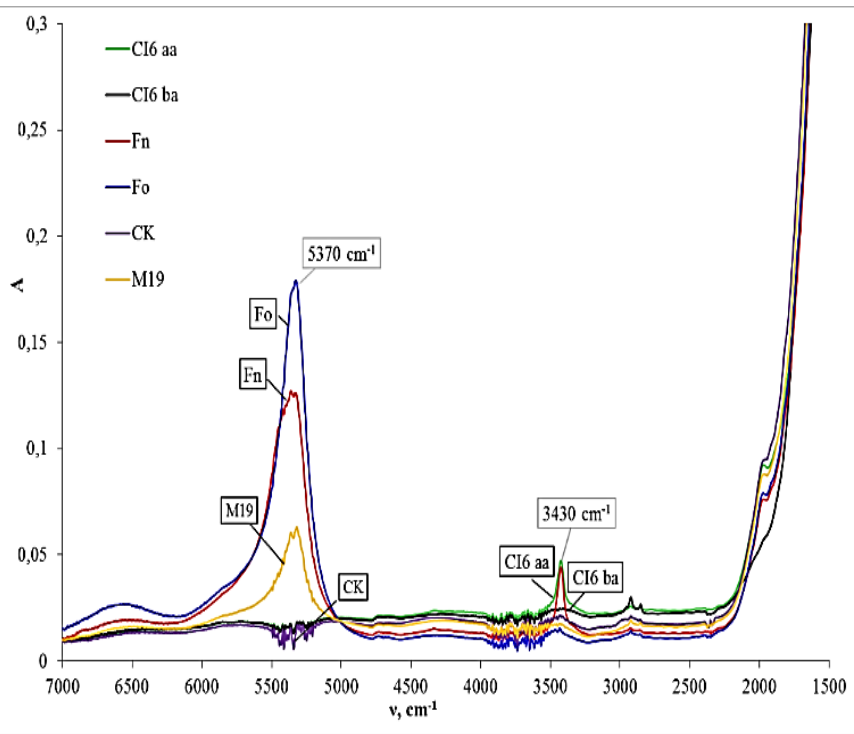

Figure 3: IR absorption spectra of LGT samples.

We attribute the absorption bands at $5370 \mathrm{~cm}^{-1}$ and at $3430 \mathrm{~cm}^{-1}$ to electronic transitions. For LGT Fo, we note that ultraviolet irradiation generates additional absorption band at $5400 \mathrm{~cm}^{-1}$. While the spectrum of CK sample, which does not exhibit a peak at $5370 \mathrm{~cm}^{-1}$, has not changed after irradiation, Figure 4 .

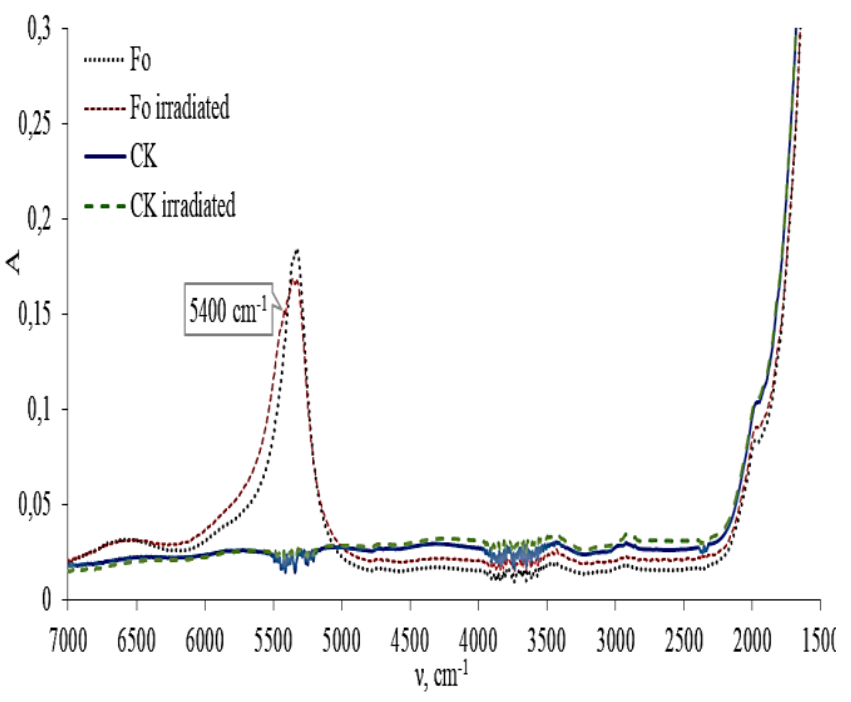

Figure 4: Ultraviolet irradiation effect on IR absorption spectra of LGT samples ' $F o$ ' and ' $C K$ '.
Comparing IR absorption spectra of LGT Fn and LGS, Figure 5, we note that LGT transmission edge is at higher wavelength and LGS spectrum exhibits an additional absorption band at $\sim 2650 \mathrm{~cm}^{-1}$. For LGS, we note that ultraviolet irradiation increases the intensity of the absorption band at $5400 \mathrm{~cm}^{-1}$, Figure 5.

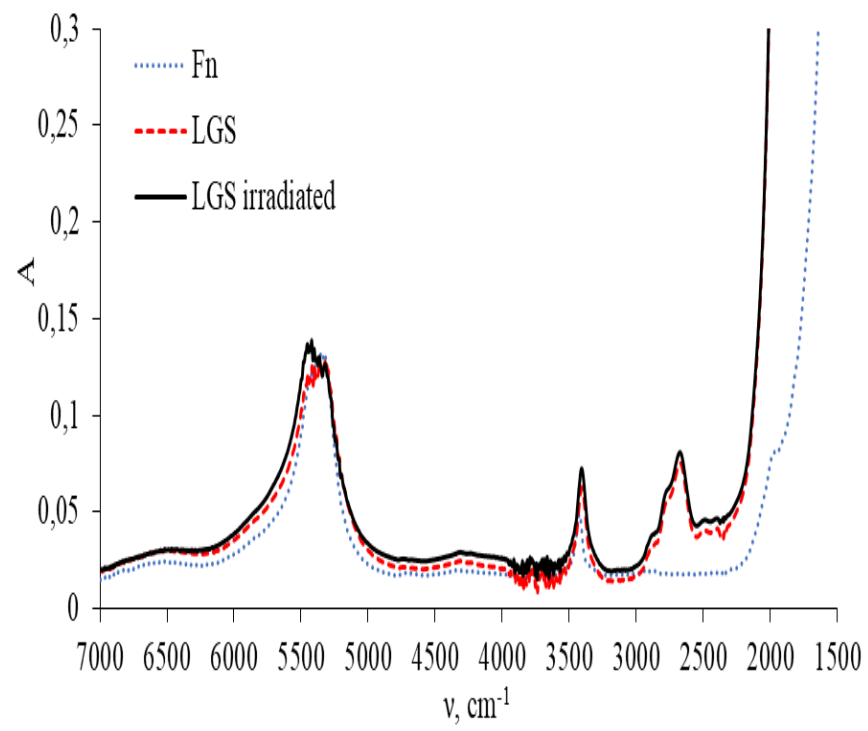

Figure 5: Comparison between IR absorption spectra of LGT 'Fn', LGS and irradiated LGS samples.

\section{Discussion}

\subsection{Metal Ions Impurities}

The yellow-orange color of LGT crystal can be due to light absorption by transition metals $(\mathrm{Fe}, \mathrm{Ti}, \mathrm{Cu})$ and rare-earth elements $(\mathrm{Ce}, \mathrm{Pr}, \mathrm{Nd})$ impurities under the effect of the electrical field of neighboring oxygen ions. According to chemical analyses performed by Femtosecond laser ablation/ICP-MS coupling (Fs LA-ICP-MS) on LGT 'CI6 aa' and LGT 'Fn'[3], raw materials impurities, in particular metal transition ions such as $\mathrm{Fe}$ and $\mathrm{Ti}$ and lanthanide such as $\mathrm{Ce}$ and $\mathrm{Pr}$, have contaminated grown LGT crystals and can contribute to their color. This is also confirmed by electron spin resonance (ESR) spectra of these LGT samples, which show a spin transition at $\mathrm{g}$ between 4.2 and 4.3, characteristic of $\mathrm{Fe}^{3+}$ in tetrahedral environment and a spin transition at $\mathrm{g}$ between 2.42.1 which is characteristic of $\mathrm{Fe}^{2+}$ in octahedral environment [3]. Moreover, Fs LA-ICP-MS chemical analyses [3] show that the concentrations of transition metal ions impurities increase with the color intensity 
Allani et al., Int. Ann. Sci.; Vol. 2 Issue 1, pp: 12-19, April 2017

of LGT crystals. LGT crystals are commonly grown by Czochralski method using an Iridium crucible [5] [6] [10] [15]. Kimura et al. [15] reported that LGT crystals contain iridium ions, which are responsible to the crystal color. However, Fs LA-ICP-MS chemical analyses [3] show that iridium concentration in LGT crystals is below 1 ppm. The as-grown LGT CI6ba in $\mathrm{N}_{2}$ atmosphere has been colorless and it became orange after annealing in oxygen containing atmosphere Figure 1. I.A. Kaurova et al. [13] found also that the color of LGT crystal grown by Czochralski technique under a 99\% $\mathrm{Ar}+1 \% \mathrm{O}_{2}$ atmosphere changed after air annealing from light yellow to orange. Annealing affects a color by modifying the valence state [18] of dispersed metal ions. For example, $\mathrm{Fe}^{2+}$ can be oxidized into $\mathrm{Fe}^{3+}$ by annealing LGT crystals in oxidizing conditions and then LGT color will change.

\subsection{Charge Transfer}

The optical transmission spectrum of bright orange LGT Fn sample, Figure 2, shows an absorption centered in the near ultraviolet and extended into the blue end of the visible spectrum. It can be due to an interaction between transition metal ions and its neighbors in the LGT structure. The ultraviolet absorption cannot simply be due to metal ions transition.

\subsubsection{Oxygen-cation Charge Transfer}

The yellow-orange color of LGT crystals can result from light absorbed through the transfer of electrons from the oxygen ions to the metal transition ions impurities such as $\mathrm{O}^{2-} \rightarrow \mathrm{Fe}^{3+}$. E. Fritsch et al. [19] reported that oxygen-metal charge transfer absorptions produce yellow to orange and brown colors independently of the nature of the host mineral. For example, the yellow color of corundum $\mathrm{Al}_{2} \mathrm{O}_{3}$ [20] and quartz $\mathrm{SiO}_{2}$ 'citrine' [21] is caused by light absorption through $\mathrm{O}^{2-} \rightarrow \mathrm{Fe}^{3+}$ charge transfer. Annealing in Oxygen containing atmosphere changes LGT CI6ba from colorless to orange colored, Figure 1. First, heat treatment can induce or increase charge transfers. Second, annealing in oxygen containing atmosphere can oxidize transition metal ions impurities. As the positive charge of the central metal ion increases, the absorption band of the Oxygen $\rightarrow$ metal ion charge transfer moves from the ultraviolet toward the visible region [19] and then crystal changes from colorless to orange colored.

\subsubsection{Cation-Cation Charge Transfer}

The orange color of LGT crystal can be due to intervalence charge transfer between metal ions in the appropriate valence states. During annealing, metal ions impurities such as $\mathrm{Fe}^{2+}$ can be partially oxidized and, through diffusion, pairs of $\mathrm{Fe}^{2+}$ and $\mathrm{Fe}^{3+}$ ions can be formed, which interact through $\mathrm{Fe}^{2+}-\mathrm{Fe}^{3+}$ intervalence charge transfer by light absorption in the blue end of the spectrum to yield the orange coloration. The yellow-orange color of LGT crystal can be due to light absorption by ion pair transitions such as $\mathrm{Fe}^{3+}-\mathrm{Fe}^{3+}$. These absorptions arise from a transition that occurs simultaneously in both ions. They are situated between 300 and $500 \mathrm{~nm}$ and generate yellow to red colors. Such transitions are very strongly oriented along the $\mathrm{Fe}^{3+}-\mathrm{O}-\mathrm{Fe}^{3+}$ bonds As a result, they induce pleochroism [19]. $\mathrm{Fe}^{3+}-\mathrm{Fe}^{3+}$ pair transitions are mentioned by J.Ferguson et al [22] to elucidate the color of some yellow sapphires $\alpha$ $\mathrm{Al}_{2} \mathrm{O}_{3}$ and by S. M Mattson et al [23] to explain the hue of some red crystalline boron silicate called 'dravites'.

\subsection{Color Centers}

\subsubsection{Electron Color Centers}

Electron color centers contribute to LGT crystal color. They can result from hypervalent impurities, and oxygen anions vacancies. According to Femtosecond laser/ICP-MS coupling chemical analysis [3], LGT crystals contain impurities that can occupy interstitial sites or substitute cations of the crystal lattice having or not the same degree of oxidation. If the impurity substitutes a cation with lower valence state such as Titanium cation $\mathrm{Ti}^{4+}$ substitutes Gallium cation $\mathrm{Ga}^{3+}, \mathrm{Ti}_{\mathrm{Ga}}{ }^{\bullet}$, in order to keep electroneutrality, an available electron will be trapped nearby. This is an electron color center which can contribute to LGT crystal color. It was stated in [24] that the color of LGS crystals is caused by the presence of oxygen vacancies and their complexes in the form of $F$ centers $\left(V_{O} \ddot{O}, 2 \text { e' }\right)^{x}$. The authors [4] [5] [11] examined the relationship between the coloration of LGT crystals and their composition by $\mathrm{X}$-ray and neutron diffraction. They observed that LGT crystal color depends on the growth atmosphere and the post growth treatment, and it is 
related to the concentration of oxygen vacancies complexes $\left(\mathrm{V}_{\mathrm{O}} \cdot, 2 \mathrm{e} \mathrm{e}^{\prime}\right)$ x.

H. Kimura et al [15] and O.A Busanov et al [16] observed that the color of LGS and LGT crystals depends on the oxygen partial pressure in growth atmosphere. The color of LGT crystals decreases progressively in intensity when the Oxygen concentration in an Argon-Oxygen growth atmosphere is reduced [16]. Different researchers [4] [5] [9] [11] [13] studied the relationship between the color and the composition of LGT crystals using Xray (XRD) and neutron diffraction (ND). They conclude that the color of such crystals depends on their oxygen vacancy content and that colored crystals have less oxygen vacancies. We can conclude that Oxygen content in growth atmosphere decreases oxygen vacancies and leads to colored crystals according to quasi-chemical reaction (1). I.A Kaurova et al. [4] stated that LGT crystals were colorless for $\ddot{V}_{O}>\left(\ddot{V}_{O}, 2 e\right)^{\times}$and exhibited a color for $\ddot{V}_{O}<$ $\left(\ddot{V}_{O}, 2 \dot{e}\right)^{\times}$

$$
\frac{1}{2} O_{2}+\ddot{V}_{O}+2 \dot{e} \leftrightarrow O_{O} \times
$$

Annealing in oxygen containing atmosphere has changed LGT CI6ba from colorless to orange colored, Figure 1. Kaurova et al. [4] reported that air annealing increases the Oxygen content of the colorless sample and the crystal turned orange; vacuum annealing increases the oxygen vacancy concentration of the yellow sample, especially at annealing temperatures higher than $1200^{\circ} \mathrm{C}$ and the crystal becomes colorless [4]. G.M. Kuz'micheva et al. [5] reported that in oxygen-free growth atmosphere of langasite family, a dissociation of the melt and evaporation of Gallium suboxide are observed, which results in deficiency of Oxygen and Gallium. For that, LGT CI3 and CI6 have been grown in $\mathrm{N}_{2}$ atmosphere from Gallium rich charge composition to compensate the loss of gallium.

The site occupancy of the "octahedral" sites, equally occupied by the $\mathrm{Ga}^{3+}$ and $\mathrm{Ta}^{5+}$ cations in the stoichiometric composition $\mathrm{La}_{3} \mathrm{Ga}_{5.5} \mathrm{Ta}_{0.5} \mathrm{O}_{14}$, can be written as $\mathrm{Ga}: \mathrm{Ta}=1-\mathrm{x}: \mathrm{x}$, where $0<\mathrm{x}<1$. To maintain electroneutrality, cation and anion vacancies will form.

If $0<\mathrm{x}<0.5 \mathrm{GaTa}_{\mathrm{Ta}}$ " (Gallium rich melt composition), the crystal will be negatively charged and electroneutrality will be ensured by oxygen vacancies according to the quasi chemical reactions (2).
$\mathrm{Ga}_{2} \mathrm{O}_{3} \rightarrow 2 \mathrm{Ga}_{\mathrm{Ta}} "+2 \ddot{\mathrm{V}}_{\mathrm{O}}+3 \mathrm{O}_{\mathrm{O}}$

In this case, the composition of LGT crystal can be written as $\mathrm{La}_{3}\left(\mathrm{Ga}_{1-\mathrm{x}} \mathrm{Ta}_{\mathrm{x}}\right) \mathrm{Ga}_{5} \mathrm{O}_{14-(0.5-\mathrm{x})}$, where $0<\mathrm{x}<0.5$

\subsubsection{Hole Color Centers}

If an electron is missing from a location where usually an electron pair exists, a "hole" color center is created. If LGT crystal impurities [3] substitute cations of the crystal lattice with higher valence state such as $\mathrm{Fe}_{\mathrm{Ta}}{ }^{\prime \prime}$, $\mathrm{Fe}^{3+}$ substitutes Tantalum cation $\mathrm{Ta}^{5+}$, in order to maintain the electroneutrality, monovalent cations $\left(\mathrm{Na}^{+}, \mathrm{K}^{+}, \mathrm{H}^{+}\right)$will be present nearby. This causes forces on the electrons of the oxygen atom near the Aluminium ion to be weakened and an extreme heat can remove one of the weaker bonded electrons of the oxygen atoms that can be trapped by the monovalent cation. This leaves a hole and different energy levels become available to the new unpaired electron on the oxygen ion.

\subsection{Interband Transitions}

The color of LGT can arise through its electronic structure (band theory). In this case, transitions between bands rather than between energy levels of single atoms are responsible for the color. In fact, crystal defects such as impurities, atom vacancies and interstitial atoms contribute to the band gap narrowing by introducing new energy levels. To predict how the defects altered the electronic properties of the host materials, Chan-Yeup Chung et al [25] performed DFT calculations of band gap energy of perfect and defect-containing LGT crystals with the hybrid functional HSE06. The calculated band gap of defect-free LGT was $5.279 \mathrm{eV}$ and the calculated band gap corresponding to each defective system were $4.849 \mathrm{eV}, 4.399 \mathrm{eV}, 4.027 \mathrm{eV}, 4.050 \mathrm{eV}$, $4.348 \quad \mathrm{eV}, \quad$ and $\quad 3.678 \mathrm{eV}$ for $G a_{T a}^{\prime \prime}, V_{L a}^{\prime \prime \prime}, V_{T a}^{\prime \prime \prime \prime \prime}, V_{G a(1 a, o c t)}^{\prime \prime \prime}, V_{G a(3 f, t e t)}^{\prime \prime \prime}, \quad$ and $V_{G a(2 d, t e t)}^{\prime \prime \prime}$, respectively.

We can qualitatively determine the band gap energy of LGT crystal from the UV-Visible transmission spectrum. However, this is only the case if the interband transition is the dominant mechanism of absorption. The fundamental absorption edge of LGT crystal is $242 \mathrm{~nm}$ [27]. A spread and a shift to higher wavelengths of the intrinsic absorption edges of LGT crystals under study are shown in Figure 2. 
Allani et al., Int. Ann. Sci.; Vol. 2 Issue 1, pp: 12-19, April 2017

\section{Conclusions}

$\mathrm{La}_{3} \mathrm{Ga}_{5 .} \mathrm{Ta}_{0.5} \mathrm{O}_{14}$ crystals (LGT) differ from colorless to yellow-orange or pale-green depending on the feedstock, the growth and the post-growth treatment parameters and on trapped defects during the synthesis. The yellow-orange color is caused mainly by an absorption centered in the ultraviolet that extends into the blue of the visible spectrum (250-500 nm) and absorbs violet and blue. After ultraviolet irradiation $(\lambda=266 \mathrm{~nm})$, we note that the absorption band at $\sim 490 \mathrm{~nm}$ splits into two absorption bands at $\sim 480$ and $\sim 510 \mathrm{~nm}$. We have discussed phenomenon that can occur simultaneously in langatate crystals and produce very similar colors. First, according to fs-laser ablation ICP-MS coupling chemical analyses, LGT crystals contain metal transition impurities coming from raw materials, such as Iron and Titanium, which absorb visible light and contribute to the color. Second, the ultraviolet absorption leads us to think about charge transfer from oxygen ions to the metal transitions ions such as $\mathrm{O}^{2-} \rightarrow \mathrm{Fe}^{3+}$ and ion pair transitions such as $\mathrm{Fe}^{3+}-\mathrm{Fe}^{3+}$. Third, we have observed that ultraviolet irradiation induces the orange color by the creation of color centers. We have discussed different forms of color centers that can occur in the LGT structure such as $\left(\mathrm{V}_{\mathrm{O}} \cdot{ }^{\prime}, 2 \mathrm{e}^{\prime}\right)^{\mathrm{x}}$ and we have presented its origins. Oxygen vacancies, $\mathrm{V}_{\mathrm{O}}$, , are linked to the oxygen content in growth and annealing atmospheres. Finally, point defects reduce the band gap energy to the visible light range and LGT color can be caused by transitions between bands.

\section{Acknowledgments}

This work was funded by the "Agence Nationale de la Recherche" in the framework of a French research program ASTRID (supported by French MOD through DGA) with the project entitled "ECLATEMPS2012".

We gratefully acknowledged Dr Bernard GauthierManuel (from FEMTO-ST) for his help and advice for IR and UV-Visible spectra and Pr Olivier Cambon (from Université de Montpellier) for his help in interpreting ESR spectra.

Our thanks also go to Dr C. Klemenz-Rivenbark for very profitable talks about crystal growth of LGT.

\section{How to cite this article:}

Ohioma, O., Ezomo, F., \& Akinsunmade, A. (2017). Delineation of Hydrothermally Altered Zones that Favour Gold Mineralization in Isanlu Area, Nigeria Using Aeroradiometric Data. International Annals of Science, 2(1), 20-27. doi: https://doi.org/10.21467/ias.2.1.20-27

\section{References}

[1] R. C. Smythe, R. C. Helmbold, G. E. Hague, and K. A. Snow, "Langasite, langanite, and langatate bulk-wave Y-cut resonators," IEEE Trans. Ultrason. Ferroelectr. Freq. Control, vol. 47, no. 2, pp. 355-360, Mar. 2000.

[2] J. J. Boy et al., "New LGT crystal for ultra-stable resonators," in European Frequency and Time Forum (EFTF), 2014, 2014, pp. $75-78$

[3] M. Allani et al., "How to qualify LGT crystal for acoustic devices?," in Frequency Control Symposium \& the European Frequency and Time Forum (FCS), 2015 Joint Conference of the IEEE International, 2015, pp. 100-105.

[4] I. A. Kaurova, G. M. Kuz'micheva, V. B. Rybakov, A. B. Dubovskii, and A. Cousson, "Composition, structural parameters, and color of langatate," Inorg. Mater., vol. 46, no. 9, pp. 988-993, 2010.

[5] G. M. Kuz'micheva et al., "The color of langatate crystals and its relationship with composition and optical properties," Cryst. Res. Technol., vol. 47, no. 2, pp. 131-138, 2012.

[6] O. A. Buzanov, E. V. Zabelina, and N. S. Kozlova, "Optical properties of lanthanum-gallium tantalate at different growth and post-growth treatment conditions," Crystallogr. Rep., vol. 52, no. 4, pp. 691-696, Jul. 2007.

[7] H. Kawanaka, H. Takeda, K. Shimamura, and T. Fukuda, "Growth and characterization of La3Ta0.5Ga5.5O14 single crystals," J. Cryst. Growth, vol. 183, no. 1, pp. 274-277, Jan. 1998.

[8] B. Chai, J. L. Lefaucheur, Y. Y. Ji, and H. Qiu, "Growth and evaluation of large size LGS (La3Ga5 SiO14) LGN (La3Ga5.5Nb0.5 O14) and LGT (La3Ga5.5Ta0.5 O14) single crystals," in Proceedings of the 1998 IEEE International Frequency Control Symposium (Cat. No.98CH36165), 1998, pp. 748-760.

[9] G. M. Kuz'micheva, E. A. Tyunina, E. N. Domoroshchina, V. B. Rybakov, and A. B. Dubovskii, "X-ray diffraction study of La3Ga5.5Ta0.5O14 and La3Ga5.5Nb0.5O14 langasite-type single crystals," Inorg. Mater., vol. 41, no. 4, pp. 412-419, Apr. 2005

[10] G. M. Kuzmicheva, E. N. Domoroschina, V. B. Rybakov, A. B. Dubovsky, and E. A. Tyunina, "A family of langasite: growth and structure," J. Cryst. Growth, vol. 275, no. 1-2, pp. e715-e719, Feb. 2005.

[11] G. M. Kuz'Micheva et al., "Point defects in langatate crystals," Crystallogr. Rep., vol. 54, no. 2, pp. 279-282, 2009.

[12] H. Takeda, K. Sugiyama, K. Inaba, K. Shimamura, and T. Fukuda, "Crystal Growth and Structural Characterization of New Piezoelectric Material La3Ta0.5Ga5.5O14,” Jpn. J. Appl. Phys., vol. 36, no. 7B, pp. L919, Jul. 1997.

[13] I. A. Kaurova, G. M. Kuz'micheva, and A. B. Dubovskii, "Physicochemical properties of La3Ga5.5Ta0.5O14," Inorg. Mater., vol. 46, no. 10, pp. 1131-1136, Oct. 2010.

[14] T. Taishi, N. Bamba, K. Hoshikawa, and I. Yonenaga, "Single crystal growth of langataite (La3Ta0.5Ga5.5O14) by vertical Bridgman (VB) method along [2 $\left.1^{-} 1^{-} 0\right]$ in air and in an $\mathrm{Ar}$ atmosphere," J. Cryst. Growth, vol. 311, no. 1, pp. 205-209, Dec. 2008. 
[15] H. Kimura, S. Uda, O. Buzanov, X. Huang, and S. Koh, "The effect of growth atmosphere and Ir contamination on electric properties of La3Ta0.5Ga5.5O14 single crystal grown by the floating zone and Czochralski method," J. Electroceramics, vol. 2, no. 20, pp. 73-80, 2008.

[16] O. A. Buzanov, N. S. Kozlova, E. V. Zabelina, A. P. Kozlova, and N. A. Siminel, "Optical transmission spectra and electrical properties of langasite and langatate crystals as dependent on growth conditions," Russ. Microelectron., vol. 40, no. 8, pp. 562-566, 2011.

[17] M. Alani et al., "Influence of the growth and annealing atmosphere on the electrical conductivity of LTG crystals," Opt. Mater., vol. 65, pp. 99-102, 2017.

[18] E. Fritsch and G. R. Rossman, "An update on color in gems. Part 1: Introduction and colors caused by dispersed metal ions," Gems Gemol., pp. 126-139, 1987.

[19] E. Fritsch and G. R. Rossman, "An Update on Color in Gems. Part 2: Colors Involving Multiple Atoms and Color Centers," Gems Gemol., vol. 24, no. 1, pp. 3-15, Mar. 1988.

[20] H. H. Tippins, "Charge-transfer spectra of transition-metal ions in corundum," Phys. Rev. B, vol. 1, no. 1,pp. 126, 1970.

[21] V. S. Balitsky and O. V. Balitskaya, "The amethyst-citrine dichromatism in quartz and its origin," Phys. Chem. Miner., vol. 13, no. 6, pp. 415-421, 1986.

[22] J. Ferguson and P. E. Fielding, "The origins of the colours of yellow, green and blue sapphires," Chem. Phys. Lett., vol. 10, no. 3 , pp. $262-265,1971$.
[23] S. M. Mattson and G. R. Rossman, "Ferric iron in tourmaline," Phys. Chem. Miner., vol. 11, no. 5, pp. 225-234, 1984.

[24] E. N. Domoroshchina, "Effect of Growth Conditions on the Composition, Structure, and Properties of Langasite-Family Crystals," in Extended Abstract of Cand. Sci.(Chem.) Dissertation, pp. 24, 2005.

[25] C.-Y. Chung, R. Yaokawa, H. Mizuseki, S. Uda, and Y. Kawazoe, "First principles calculation of La 3 Ta 0.5 Ga $5.5 \mathrm{O}$ 14 crystal with acceptor-like intrinsic point defects," J. Appl. Phys., vol. 108, no. 11, pp. 113505, 2010.

\section{Publish your research article in AIJR journals-}

$\checkmark$ Online Submission and Tracking

$\checkmark$ Peer-Reviewed

$\checkmark$ Rapid decision

$\checkmark$ Immediate Publication after acceptance

$\checkmark$ Articles freely available online

$\checkmark$ Retain full copyright of your article.

Submit your article at journals.aijr.in 